\title{
Application of Polymers in Low Permeability Formations
}

\author{
Juan Zhao',2, Caili Dai³, Guang Yang1,2, Jian Zhang1,2, Hui Yang4, Xinsheng Xue1,2, \\ Xiaodong Kang1,2, Lixia Li1,2 \\ ${ }^{1}$ State Key Laboratory of Offshore Oil Exploitation, Beijing, China \\ ${ }^{2} \mathrm{CNOOC}$ Research Institute, Beijing, China \\ ${ }^{3}$ China University of Petroleum (East China), Qingdao, China \\ ${ }^{4}$ Key Laboratory of Colloid, Interface and Chemical Thermodynamics, Institute of Chemistry, the Chinese \\ Academy of Sciences, Beijing, China \\ Email: zhaojuanupc@163.com
}

Received 3 April 2015; accepted 3 May 2015; published 7 May 2015

Copyright ( 2015 by authors and Scientific Research Publishing Inc.

This work is licensed under the Creative Commons Attribution International License (CC BY).

http://creativecommons.org/licenses/by/4.0/

(c) ()

\section{Abstract}

For low-permeability sandstone reservoir with big channel, we researched the novel deep profile method alternative injection of anionic and cationic polymer. Evaluating various factors on adsorption capacity through lab test, the results show that with the increase of temperature, the adsorption capacity decreases and the cationic polymer is easier to be absorbed. With the increase of salinity, adsorption time or polymer concentration, the adsorption capacity increases. The adsorption equilibrium concentration of cationic polymer is $1500 \mathrm{mg} / \mathrm{L}$; adsorption equilibrium time is $8 \mathrm{~h}$. The adsorption equilibrium concentration of anionic polymer is $1000 \mathrm{mg} / \mathrm{L}$; adsorption equilibrium time is $6 \mathrm{~h}$. Physical simulation experiment shows that alternative injection of anionic and cationic polymer is better than injection of single polymer, and preferential injection of cationic polymer is better than preferential injection of anionic polymer. With the increase of injection rounds, sealing capacity gets better, but in view of cost, the rounds should not be more than 3 . The profile control technique can obviously enhanced oil recovery, and water displacement recovery increases 41\%. 2 wells were tested successfully in Henan Oilfield in June 2010. Approximate 154.47 tons of incremental oil was obtained with $2 \%$ water-cut decrease.

\section{Keywords}

Anionic and Cationic Polymer, Alternative Injection, Sealing Capacity, Water Displacement Recovery Increment 


\section{Introduction}

Low permeability oil fields are in wide distribution in China [1], along with the petroleum resources continuous consuming, more and more low permeability oil fields have been exploitated. For the low permeability oil fields has bad reservoir physical property and bad injectivity, the profile control agent [2]-[4] must be not only increasing injection in near borehole zones but also profile control in areas far from the borehole, and the profile control agent can entry the deep formation, will not completely blocking the near bore zones. Deep profile method [5] is alternative injection of anionic and cationic polymer into the water well. The polymer solution has priority to enter the high permeability reservoir with high water saturation [6]-[7], and adsorbs the rock surface relying on the function of hydrogen bonds and electrostatic attraction. The macromolecular chains exist in the form of in coli, and it can form mutilayer adsorption on rock surface, reduce the water channel, and force the subsequent water to flood low-permeability reservoir so that it can enhance the sweep efficiency, thus this method can enhance oil recovery. The paper mainly studies the adsorption capacity of the anionic and cationic polymer, selects the optimized injection order and injection turn, and researches the flushing resistance performance and EOR of the deep profile control agent.

\section{Experiment}

\subsection{Experiment Principle}

The injected polymer firstly entries high water saturation formation, then form multi-point adsorption on surface of the sandstone formation relies on the hydrogen bond, dispersion force and electrostatic attraction [8]. The part without adsorption of the polymer molecular can extend in the water, decreases water penetrability.

Suppose first inject cationic polymer, because the sandstone formation has negative electricity [9], the polymer adsorbs the formation by electrostatic attraction, dispersion force, hydrogen bond, so it forms the first adsorption layer. Then we inject anionic polymer, the anionic polymer adsorbs to the cationic adsorption layer through the electrostatic attraction and dispersion force, it forms multilayer adsorption formation while constantly alternating injection, which can decreases water channel, and it plays a role of profile control. The mechanism of preferential injection of anionic polymer is similar to the cationic polymer, and it forms the first adsorption layer through the function of dispersion force and hydrogen bond.

\subsection{Experiment Materials}

The chemicals include: cationic polymer (parameters are shown in Table 1), anionic polymer (parameters are shown in Table 1), starch, cadmium iodide, sodium acetate, sodium formate, aluminum sulfate, $\mathrm{NaCl}$.

\subsection{Experiment Methods}

\subsubsection{Determination of Static Adsorption Capacity}

Adopt starch-cadmium iodide method in reference [10], measure the absorbance of the two polymer solutions before and after the adsorption, in order to figure out the mass concentration of the polymers solution, then figure out the static adsorption amount.

\subsubsection{Determination of Plugging Performance}

Use plugging rate to evaluate the shut off capacity of plugging agent, and the flow schematic drawing follows Figure 1. Test procedures: 1) weigh dry weight of sand pack; 2) evacuate and saturate water; 3) weigh wet weight of sand pack; 4) account the pore volume; 5) measure the initial waterflood permeability $k_{0}$; 6) inject profile control agent as much as one time pore volume; 7) measure the permeability $k_{1}$ after blocking. The plugging rate formula is:

$$
E=\left(k_{0}-k_{1}\right) / k_{0}
$$

\subsubsection{Determination of Recovery Increment}

Water displacement recovery increment refers to the difference of after injecting profiling agent and water drive, and use double sand pack model to measure it, flow schematic drawing follows Figure 2. Test procedures: 1) weigh the two dry weight of sand pack; 2) saturated formation water; 3) weigh the wet weight of the two sand 


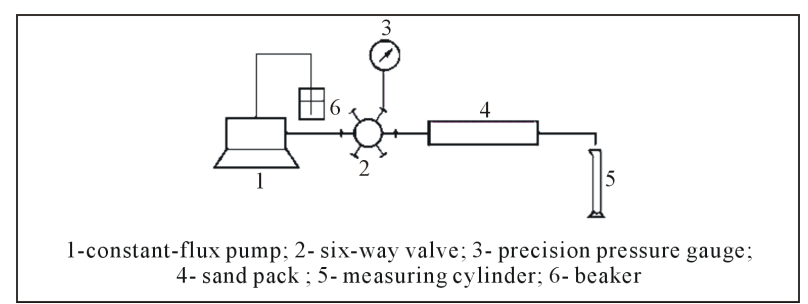

Figure 1. The measuring device of single sandpack model.

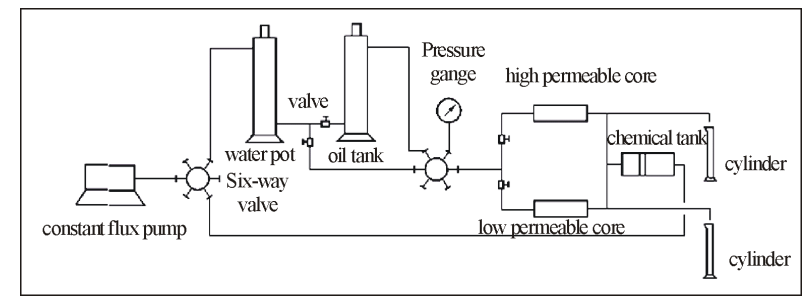

Figure 2. The recovery increment measuring device of double sandpack model.

Table 1. The basic property of polymer.

\begin{tabular}{ccccc}
\hline polymer & solid content/\% & molecular weight & cationic degree/\% & hydrolyzing degree/\% \\
\hline cationic polymer & 85.85 & $824 \times 10^{4}$ & 33.48 & - \\
anionic polymer & 90.2 & $1247 \times 10^{4}$ & - & 24.38 \\
\hline
\end{tabular}

packs; 4) separately measure the permeability of the two sand packs; 5) separately saturate formation oil to the two sand packs; 6) parallel sand pack and water flooding until water cut is 98\%; 7) inject the profile control agent; 8) wait until adsorption is saturated under formation temperature; 9) water drive until the water cut is $98 \% ; 10)$ calculate the recovery increment.

\section{Results and Discussion}

\subsection{Influence Factors of Static Adsorption Capacity}

Within the specific scope, the more adsorption amount of polymer, the better to the polymer flooding. Although the polymer solution concentration gets thinner because of the adsorption, the solution viscosity decreases, but the water phase permeability decreases because of adsorption, which not only improve mobility ratio but also adjust the profile of water phase permeability. We mainly research the factors that such as the polymer concentration, temperature, salinity, adsorption time and shear rate on adsorption.

\subsubsection{Polymer Concentration}

At $75^{\circ} \mathrm{C}$, use distilled water to prepare different concentrations of the polymer solution, and the adsorption amount shows in the following Figure 3. Figure 3 shows that with the increase of polymer concentration, the adsorption amount increases obviously, and the adsorption of cationic polymer is more than the adsorption of anionic polymer. The higher the profile control agent concentration is, the more polymer molecules touch the rock surface, so the adsorption amount is greater. When the polymer concentration reaches a certain concentration (cationic polymer reaches $1500 \mathrm{mg} / \mathrm{L}$, anionic polymer reaches $1000 \mathrm{mg} / \mathrm{L}$ ), as the concentration adds, the adsorption has a little difference. It indicates that the static adsorption reaches saturated adsorption, so we call the concentration "adsorption balance concentration”. The sandstone formation has electronegativity, so the cationic polymer is easer adsorbed to the rock surface because of the electrostatic attraction and dispersion force.

\subsubsection{Temperature}

Use distilled water to prepare $1500 \mathrm{mg} / \mathrm{L}$ cationic polymer and $1000 \mathrm{mg} / \mathrm{L}$ anionic polymer, the adsorption at 
different temperature is seen form Table 2. Table 2 presents that with the increase of temperature, the adsorption reduces. The reasons include: 1 ) the adsorption process is exothermic reaction, so the adsorption reduces when the temperature increases; 2) the temperature has impact on solubility, the solubility of the polymer increases when the temperature rises, but the larger solubility the smaller adsorption amount; 3 ) as the temperature rises, the polymer molecular activity increases, which urge the polymer molecular to escape from the sandstone.

\subsubsection{Salinity}

At $75^{\circ} \mathrm{C}$, use distilled water and sodium chloride to get the different mineralized water and then use the water to prepare $1500 \mathrm{mg} / \mathrm{L}$ cationic polymer and $1000 \mathrm{mg} / \mathrm{L}$ anionic polymer, the adsorption at different salinity is seen form Table 3. Table 3 presents with the increase of salinity, the adsorption amount increases slowly. The reasons include: 1) as the salinity increases, the interaction of water molecules is strengthened, so it reduces the solubility of the polymer which dissolves relying on the hydrogen bond with water, furthermore, the adsorption adds; 2) for the anionic polymer, the cations increase, so increases the chance of entering adsorption layer from diffusion layer for cations, lead to the electronegativity of sandstone surface and anionic polymer molecular reducing. The diffuse double layers of sandstone surface and anionic polymer molecular are weakened, so the relative gravity increases, and the adsorption adds. As the salinity increases, the cations in the solution which inhibits the dissociation of carboxyl, lead the diameter of anionic polymer molecular becoming small, increasing the adsorption point, so the adsorption amount adds.

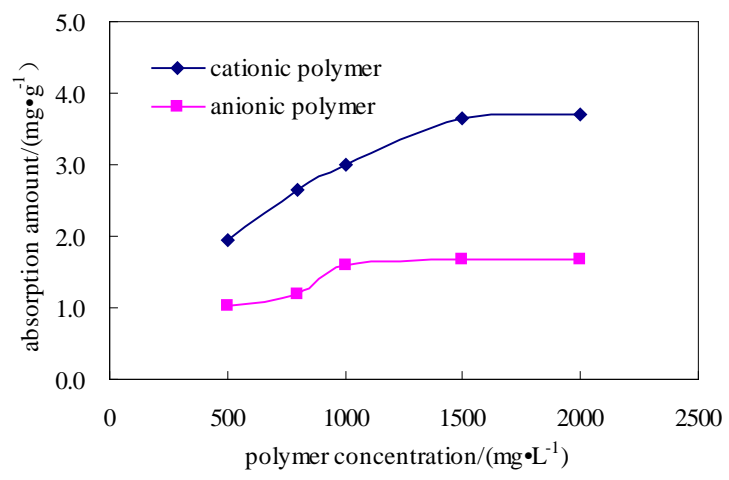

Figure 3. Effect of polymer concentration on adsorption capacit.

Table 2. Effect of temperature on adsorption capacity.

\begin{tabular}{ccc}
\hline temperature ${ }^{\circ} \mathrm{C}$ & cationic polymer adsorption amount/(mg/g) & anionic polymer adsorption amount/(mg/g) \\
\hline 60 & 3.73 & 1.74 \\
70 & 3.76 & 1.68 \\
75 & 3.65 & 1.65 \\
80 & 3.60 & 1.58 \\
\hline
\end{tabular}

\section{Table 3. Effect of salinity on adsorption capacity.}

\begin{tabular}{ccc}
\hline salinity/(mg/L) & cationic polymer adsorption amount/(mg/g) & anionic polymer adsorption amount/(mg/g) \\
\hline 3000 & 3.80 & 0.86 \\
5000 & 3.88 & 0.90 \\
10,000 & 3.98 & 0.95 \\
15,000 & 4.14 & 0.98 \\
20,000 & 4.25 & 1.01 \\
25,000 & 4.41 & 1.04 \\
\hline
\end{tabular}




\subsubsection{Adsorption Time}

At $75^{\circ} \mathrm{C}$, use distilled water to prepare $1500 \mathrm{mg} / \mathrm{L}$ cationic polymer and $1000 \mathrm{mg} / \mathrm{L}$ anionic polymer, the adsorption under different adsorption time is seen form Figure 4. Figure 4 shows that with the increase of adsorption time, the adsorption amount increases obviously, but when the adsorption time reaches a certain time, the adsorption amount increases slowly. When the cationic polymer is $8 \mathrm{~h}$ and the anionic polymer is $6 \mathrm{~h}$, the adsorption is balanced. So the adsorption time of cationic polymer is $8 \mathrm{~h}$ and the adsorption time of anionic polymer is $6 \mathrm{~h}$.

\subsubsection{Shear Rate}

At $75^{\circ} \mathrm{C}$, use distilled water to prepare $1500 \mathrm{mg} / \mathrm{L}$ cationic polymer and $1000 \mathrm{mg} / \mathrm{L}$ anionic polymer, the shearing time all is ten minutes. Table 4 shows that with the increase of shear rate, the adsorption amount reduces greatly. Because the polymer is the pseudo plastic fluid which is very sensitive to shear rate, as the shear rate increases, some notes of the molecule are damaged, and some solvent penetrating into the macromolecular is extruded, so the molecule dimension reduces, the adsorption point is not easy to adsorb onto the rock. The severe shear rate may break molecular chain, and the molecular weight wanes, the dispersion force weakens, so the adsorption amount becomes less.

\subsection{Influence Factors of Plugging Capacity}

\subsubsection{Injection Interval}

Respectively saturated formation water to three core samples by $1 \mathrm{~mL} / \mathrm{min}$, the permeability of the three core samples are all $3 \mu \mathrm{m}^{2}$. Inject $0.3 \mathrm{PV}$ cationic polymer into the core sample, then put the core sample in constant temperature water bath $8 \mathrm{~h}$ at $75^{\circ} \mathrm{C}$. Carry on water flooding to this three core samples, and the volume of water flooding respective is $1 \mathrm{PV}, 2 \mathrm{PV}, 3 \mathrm{PV}$, then inject $0.3 \mathrm{PV}$ anionic polymer into the core sample. Put the core sample in constant temperature water bath $6 \mathrm{~h}$, then measure the permeability and compute plugging rate. The cationic polymer concentration is $1500 \mathrm{mg} / \mathrm{L}$, and the anionic polymer concentration is $1000 \mathrm{mg} / \mathrm{L}$. The result follows Table 5. Table 5 shows that with the increase of injection interval, the plugging rate reduces, however the plugging rate almost no change after water flooding $2 \mathrm{PV}$. This is due to two reasons, on the one hand when the injection interval is small, the polymer can retain in the formation fluid and can form flocculent precipitate

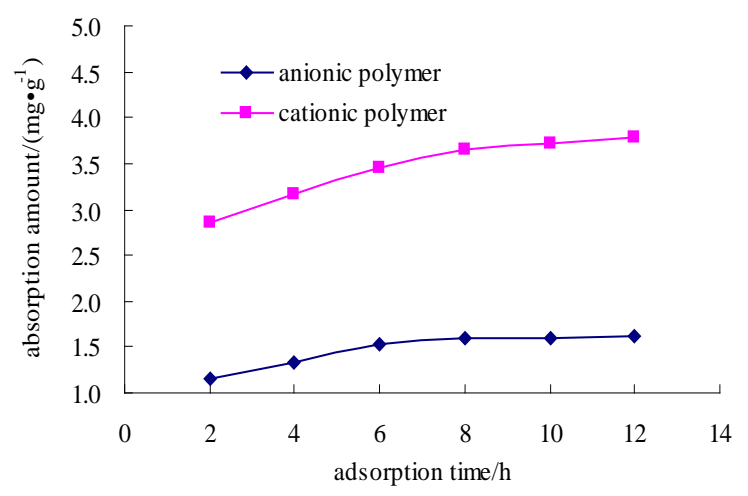

Figure 4. Effect of adsorption time on adsorption capacity.

Table 4. Effect of shear rate on adsorption capacity.

\begin{tabular}{ccc}
\hline shear rate/(r/min) & cationic polymer adsorption amount/(mg/g) & anionic polymer adsorption amount/(mg/g) \\
\hline 3500 & 3.77 & 1.47 \\
9500 & 2.24 & 1.05 \\
15,500 & 2.22 & 1.03 \\
21,500 & 1.86 & 0.53 \\
\hline
\end{tabular}


Table 5. Effect of injection interval on plugging rate.

\begin{tabular}{cccc}
\hline injection interval & initial permeability $/ \mu \mathrm{m}^{2}$ & permeability after plugging $/ \mu \mathrm{m}^{2}$ & plugging rate $/ \%$ \\
\hline PV & 3.31 & 0.15 & 95.51 \\
$2 \mathrm{PV}$ & 3.23 & 0.51 & 84.26 \\
$3 \mathrm{PV}$ & 3.28 & 0.56 & 83.03 \\
\hline
\end{tabular}

when meet counter-ion polymer; on the other hand the residual polymer is very little with the increase of injection interval, plugging channels mainly depends on multilayer adsorption layer. When the injection interval achieve $2 \mathrm{PV}$, the plugging rate no longer changes is due to the polymer mainly form multilayer adsorption layer after fully washing.

\subsubsection{Injection Order}

Saturate formation water to the sand pack which permeability is $2.5 \mu \mathrm{m}^{2}$ by $1 \mathrm{~mL} / \mathrm{min}$ at $75^{\circ} \mathrm{C}$. First, inject 0.3 VP A solution to the core sample, and wait for a certain time and water flooding 2 VP. Then inject 0.3 VP B solution and wait for a certain time and water flooding 2 VP. Determine the permeability of the core and calculate plugging rate. Then repeat to inject the profile control agent alternatively like that until the permeability is stable. The cationic polymer concentration is $1500 \mathrm{mg} / \mathrm{L}$, waiting for $8 \mathrm{~h}$, and the anionic polymer concentration is $1000 \mathrm{mg} / \mathrm{L}$, waiting for $6 \mathrm{~h}$. The result follows Table 6 . Compared to the injection method above, alternative injection of anionic and cationic polymer is better than injection of single polymer, and preferential injection of cationic polymer is better than preferential injection of anionic polymer.

\subsubsection{Injection Round}

Saturate formation water to the sand pack which permeability is $2 \mu \mathrm{m}^{2}$ by $1 \mathrm{~mL} / \mathrm{min}$ at $75^{\circ} \mathrm{C}$. First, inject $0.3 \mathrm{VP}$ cationic polymer solution to the core sample, and put it in constant temperature water bath for $8 \mathrm{~h}$ and water flooding 2 VP. Then inject 0.3 VP anionic polymer solution and put it in constant temperature water bath for $6 \mathrm{~h}$ and water flooding 2 VP. Determine the permeability of the core. Then repeat to inject the profile control agent alternatively like that until the permeability is stable. We change the injecting order of the profile control agent, first inject anionic polymer solution then cationic polymer solution. As the rounds of injection increases, the plugging rate can be shown by Figure 5. Figure 5 shows that alternative injection of anionic and cationic polymer has good plugging capacity, and all the plugging rates exceed $89 \%$. With the increase of injection rounds, sealing capacity gets better. The plugging rate changes slightly after 3 rounds, because the adsorption achieves saturated. Considering the input-output ratio comprehensively, the rounds should not be more than 3. Preferential injection of cationic polymer is better than preferential injection of anionic polymer. Meanwhile we can use this method to inject counter-ionic polymer into the formation in order to reuse the residual polymer in the formation.

\subsubsection{Permeability}

According to the process of 2.2 (2), inject anionic and cationic polymer into two sand packs which permeability are $1 \mu \mathrm{m}^{2}$ and $2 \mu \mathrm{m}^{2}$ for 3 rounds at $75^{\circ} \mathrm{C}$. The plugging rate can be seen from the Table 7 . Table 7 shows, as the permeability increases, the plugging rate reduces. This is due to two reasons, on the one hand the pore of lower permeability sand pack is narrower, the specific surface area is bigger and the adsorption amount is larger. On the other hand the bigger ratio of the effective size of polymer molecule and the size of channel, the more polymer molecules are trapped in the porous media, and the more polymers are detained.

\subsection{The Performance of Flushing Resistance}

$20 V_{\mathrm{P}}$ water was injected into the sand pack which permeability is $2.27 \mu \mathrm{m}^{2}$ made in the process of 2.2 (4), and the flow rate is $1 \mathrm{~mL} / \mathrm{min}$, the relationship between the pressure and the water injection volume can be seen from the Figure 6. We can know that after alternatively injecting the cationic polymer and anionic polymer from Figure 6 , as the water flooding volume increases, the injection pressure reduces. If the polymer is produced completely, the pressure should stay at about $0.0016 \mathrm{MPa}$. But after water flooding $10 \mathrm{PV}$, the pressure maintains $0.06 \mathrm{MPa}$ 


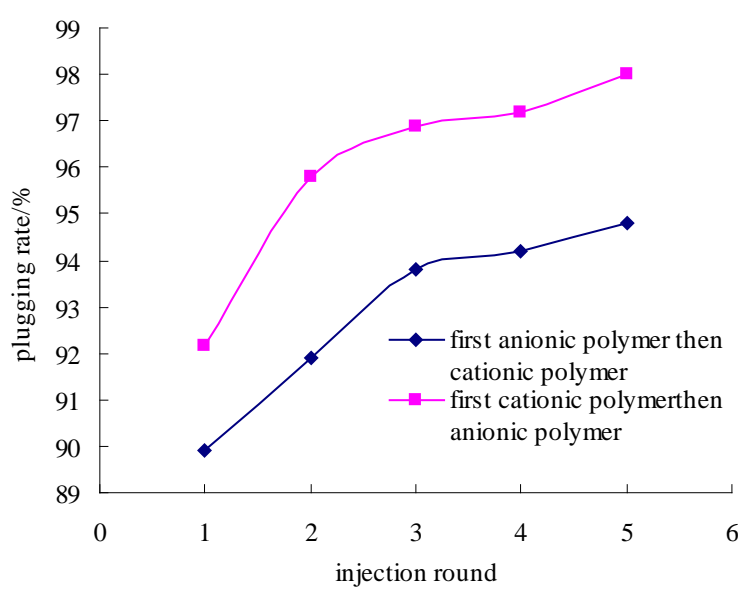

Figure 5. Effect of injection rounds on plugging rate.

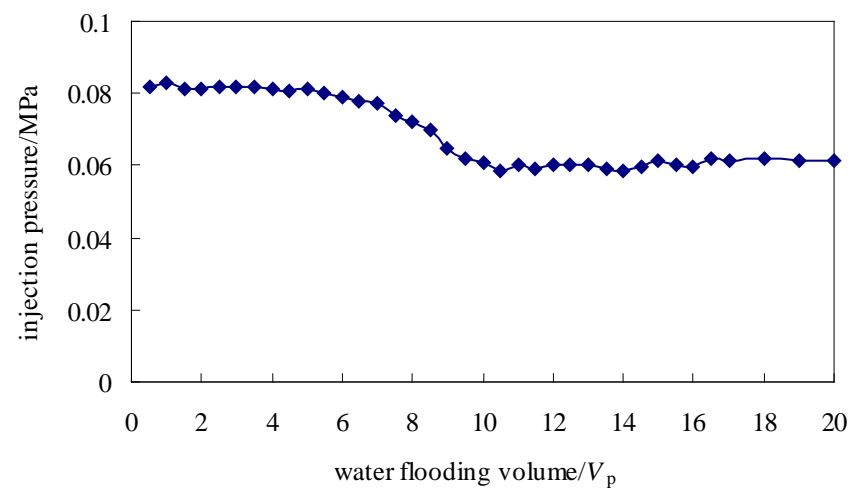

Figure 6. The relationship between the injection pressure and the water flooding volume.

Table 6. Effect of injection order on plugging rate.

\begin{tabular}{ccccc}
\hline number & A solution & B solution & permeability after plugging $/ \mu \mathrm{m}^{2}$ & plugging rate/\% \\
\hline 1 & cationic polymer & cationic polymer & 0.49 & 80.52 \\
2 & anionic polymer & anionic polymer & 2.23 & 10.59 \\
3 & cationic polymer & anionic polymer & 0.19 & 92.15 \\
4 & anionic polymer & cationic polymer & 0.25 & 89.92 \\
\hline
\end{tabular}

Table 7. Effect of permeability on plugging rate.

\begin{tabular}{|c|c|c|c|}
\hline initial permeability/ $\mu \mathrm{m}^{2}$ & rounds & permeability after plugging $/ \mu \mathrm{m}^{2}$ & plugging rate/\% \\
\hline \multirow{3}{*}{1.16} & 1 & 0.08 & 93.5 \\
\hline & 2 & 0.04 & 96.4 \\
\hline & 3 & 0.02 & 98.2 \\
\hline \multirow{3}{*}{2.27} & 1 & 0.18 & 92.1 \\
\hline & 2 & 0.10 & 95.5 \\
\hline & 3 & 0.07 & 97.1 \\
\hline
\end{tabular}


which scarcely changed, and plugging rate keeps above 95\%. It shows that the performance of flushing resistance of this plugging agent is excellent.

\subsection{Enhance Oil Recovery}

Determining the recovery by double sandpack model at $75^{\circ} \mathrm{C}$, the permibility of the two sand packs are $2 \mu \mathrm{m}^{2}$ and $0.5 \mu \mathrm{m}^{2}$. The flow rate was $1 \mathrm{~mL} / \mathrm{min}$, and the two sand packs separately saturate formation oil, then parallel sand pack and water flooding until water cut is $98 \%$. Inject $0.3 \mathrm{PV}$ cationic polymer to the two sand packs at $1500 \mathrm{mg} / \mathrm{L}$, and wait for $8 \mathrm{~h}$, then water flooding $2 \mathrm{VP}$. Inject $0.3 \mathrm{PV}$ anionic polymer to the sand packs at 1000 $\mathrm{mg} / \mathrm{L}$, waiting for $6 \mathrm{~h}$, then water flooding $2 \mathrm{VP}$. Water flooding until the water cut reaches $98 \%$, and we calculate the recovery increment. Table 8 shows that the profile control technique can obviously enhanced oil recovery, and water flooding recovery increases by $41 \%$. The high permeable core recovery increases by $16.2 \%$, and the low permeable core recovery increases by $56 \%$. The profile control technique adjusts the water injection profile, and the subsequent flow enters the low permeability layer.

\section{Field Experiences}

The alternative Injection of anionic and cationic polymer system has been applied in 2 wells successfully to adjust water absorbing profile in Henan oil field. Take the Shuangqian 6 well as an example, where the reservoir temperature is $75^{\circ} \mathrm{C}$. The water cut in these oil wells is permanently over $98 \%$ and local fingering is experienced from the injected water. The novel method was carried out from June, 2010, and the amount of chemical used is tabulated in Table 9. Up to October 5, 2010, approximate 154.47 tons of incremental oil was obtained with 2\% water-cut decrease.

\section{Conclusions}

On the basis of the laboratory studies of the novel profile correction technique based on alternative injection of anionic and cationic polymer the following conclusions can be drawn:

1) The higher temperature, the lower absorption amount. With the increase of salinity, adsorption time or polymer concentration, the adsorption capacity increases. The sandstone formation can absorb the cationic polymers more easily than anionic polymers.

2) Alternative injection of anionic and cationic polymer is better than injection of single polymer, and preferential injection of cationic polymer is better than preferential injection of anionic polymer.

3) With the increase of injection rounds, sealing capacity gets better, but in view of cost, the rounds should not be more than 3 . As the permeability of sandstone formation increases, the plugging rate of profile control agent becomes smaller. So it needs to adjust the injection rounds in the practical formation condition.

Table 8 . The recovery ratio after different displacement process.

\begin{tabular}{cccc}
\hline core & waterflooding recovery/\% & after injecting cationic polymer recovery/\% & after injecting anionic polymer recovery/\% \\
\hline high permeable core & 41.9 & 58.1 & 70.1 \\
low permeable core & 4 & 32 & 60 \\
total & 25 & 46.4 & 66 \\
\hline
\end{tabular}

Table 9. Slug design of Shuangqian 6 well.

\begin{tabular}{|c|c|c|c|}
\hline slug & formula & injection rounds & Dose $\left(\mathrm{m}^{3}\right)$ \\
\hline pretreatment slug & $0.4 \% \mathrm{JHB}$ & 1 & 110 \\
\hline pre-slug & $0.2 \%$ cationic polymer & 1 & 220 \\
\hline main slug & $0.15 \%$ cationic polymer $+0.1 \%$ anionic polymer & 3 & 660 \\
\hline spacer & sewage & 6 & 60 \\
\hline over displacing fluid & sewage & 1 & 13 \\
\hline total & & & 1063 \\
\hline
\end{tabular}


4) The water flooding recovery increases by $41 \%$ after alternative injecting the anionic and cationic polymer. The profile control agent enters into the high permeability formations and the sweep efficiency increases.

5) The novel method was successfully implemented at the Henan oil fields in June 2010. The preliminary results indicate positive response in both the oil production and change of the water cut.

\section{Acknowledgements}

The research was supported by the CNOOC Research Institute State, through Contract 2011ZX05024-004 (The topic from Twelfth Five-Year National Key Projects) and the Second Batch of Open Projects Funding from the State Key Laboratory of Offshore Oil Exploitation (CCL2013RCPS0244GNN).

\section{References}

[1] Zhu, W.Y., Ju, Y., Zhao, M., Chen, Q. and Yang, Z.M. (2002) Spontaneous Imbibition Mechanism of Flow through Porous Media and Waterflooding in Low-Permeability Fractured Sandstone Reservoir. Acta Petrolei Sinica, 23, 56-59. http://www.cnki.com.cn/Article/CJFDTotal-SYXB200206015.htm

[2] Feng, Q.H. (2006) Advanced Reservior Engineering. University of Petroleum Press, Dongying, 169-170.

[3] Xu, Y.G. and Liu, S. (2005) Study on Inflow Performance of Oil Wells in Low-Permeability Reservoirs. Acta Petrolei Sinica, 26, 77-80. http://wenku.baidu.com/view/22f58389d0d233d4b14e6967.html

[4] Zhang, T.Z., Chen, J. and Tian, N.L. (2001) The Research on Profile Control Technology of Bonan Low Permeability Oilfield. Drilling \& Production Technology, 24, 42-43.

[5] Fu, J.T., Peng, S.P., Li, A.F., et al. (2002) Experimental Study on Cationic Polymer Oil Displacement Profile Control during High Water Content Period. Petroleum Drilling Techniques, 30, 59-60.

[6] Liu, Y., Liu, Y.H., Gu, C.S., et al. (2008) Survey of the Mechanism on Ploymer Flooding. Inner Mongolia Petrochemical Industry, 21, 115.

http://wenku.baidu.com/link?url=ts2VDONqG8g4IMXGf4tbUi6GGs3krDXbmMt0OavJEo9TvTBzzkNXsgRXIpw0p ZXCE0i9BUnM1H_1bHZOQINMs-18-mmTnTgZ8RTWzdciF7W

[7] Zhao, F.L. (2001) Chemicals for Oil Recovery. University of Petroleum Press, Dongying, 58-59.

[8] Zhao, F.L. (2006) Principle of EOR. China University of Petroleum Press, Dongying, 39-41.

[9] Li, J.S., Yao, T.Y. and Liu, X.G. (2005) The Relationship between Zeta Potential of Sandstone Surface and Porous Flow Process. Journal of Northwest University: Natural Science Edition, 35, 459-462. http://www.cnki.com.cn/Article/CJFDTOTAL-XBDZ200504022.htm

[10] Guan, S.X., Fan, H.F., Duan, J.G. and Song, C.H. (2007) Examination of the Concentration of HPAM-The StarchCadmium Iodine Method. Journal of Daqing Petroleum Institute, 31, 110-112. http://www.cqvip.com/QK/92021X/2007002/24309390.html 